\title{
TAREFA
}

\section{UM CONCEITO-CHAVE DA PERSPECTIVA ACIONAL}

\section{Task - A Key Concept In The Action-Oriented Approach}

\author{
Iwona JANOWSKA ${ }^{1}$ (Universidade Jagielloński) \\ Tradução de Eduardo Nadalin, Universidade Federal do Paraná \\ José Carlos Moreira, Universidade Federal do Paraná
}

\section{APRESENTAÇÃO}

Embora o polonês não seja uma língua de status internacional, o fato de a Polônia ter sido um país de emigração resultou no caso de que, atualmente, muitos descendentes de poloneses mundo afora procuram aprender a língua de seus pais $e$ avós, quando não reaprender a sua própria língua, esquecida. Em razão disso, antes ainda de a Polônia integrar a União Europeia, já havia no país a tradição de se pensar sobre ensino de polonês como língua estrangeira. Contudo, é a partir do início deste século que os especialistas na área de polonês língua estrangeira se veem diante da tarefa de se adaptar às diretrizes da União Europeia para o ensino de LEM. O presente artigo, de Iwona Janowska, insere-se nesse processo, que é interessante na medida em que traz um novo olhar para o cenário da didática das línguas europeias: o olhar polonês. Em seu texto, a autora apresenta de modo simples e direto o seu entendimento sobre temas em voga: a abordagem acional e o conceito de tarefa segundo o Quadro Europeu Comum de Referência para o Ensino de Línguas. A autora, professora com sólida formação em ensino de francês e polonês e com vasta experiência de sala de aula, reflete sobre pontos do QECRL que permanecem em aberto, apresentando uma reflexão interessante sobre os conceitos mencionados acima. Seu artigo é, portanto, uma fonte para se refletir sobre noções e conceitos que, embora bastante presentes no

\footnotetext{
1 Linguista aplicada, professora titular do Centro de Língua e Cultura Polonesa da Universidade Jagielloński em Cracóvia (Polônia), Iwona Janowska é autora de vários artigos, livros e programas na área de didática de línguas francesa e polonesa como línguas estrangeiras. Na Polônia, fez parte da comissão que estabeleceu os níveis de conhecimento de língua estrangeira necessários ao final do ensino médio. Desde 2006, ministra cursos de formação em nível de mestrado para professores de polonês língua estrangeira. Em 2009 tornou-se secretária da Comissão Nacional de Certificação de Proficiência em Polonês Língua Estrangeira, posto que ocupa até hoje. Esteve várias vezes no Brasil, entre outros países, ministrando cursos de formação continuada para professores de polonês língua estrangeira.
} 


\section{DOSSIÊ ESPECIAL: DIDÁTICA SEM FRONTEIRAS (orgs.) \\ CHEREM, RAMMÉ, PEDRA \& OLMO \\ Revista X, vol.2, 2014}

campo da didática das línguas, com frequência deixam professores e estudantes de Letras com uma série de indagações.

RESUMO: Usado em diversas áreas da vida, o termo "tarefa" tornou-se impreciso e polissêmico. Ele também pode se referir à didática de língua estrangeira, área na qual adquiriu vários significados: desde uma tarefa simples (de gramática) até sequências de tarefas ou projetos que exigem trabalho ao longo de muitas unidades. "Tarefa" é um conceito-chave de descrição linguística incluído no Quadro Europeu Comum de Referência para as Línguas e traz uma nova dimensão para o processo de ensino/aprendizagem. Sua implementação se dá em um ambiente específico, isso implica um propósito determinado (linguístico e/ou extra-linguístico) e orienta o trabalho do aluno. A tarefa traz mudanças no papel dos professors, na didática e nas suas relações com os alunos. A fim de implementar o ensino baseado em tarefas na prática educativa, precisamos de algum referencial teórico. O objetivo deste artigo é apresentar exemplos de interpretação do conceito de "tarefa" e suas implicações didáticas no contexto da abordagem orientada para a ação.

PALAVRAS-CHAVE: tarefa; exercício; atividade; abordagem orientada para a ação; CEFR; Task Based Learning and Teaching

ABSTRACT: As a term used in many areas of life, "task" has become imprecise and polysemic. It also refers to the foreign language didactics, where it has acquired various meanings: from a simple task (grammar) to sequences of tasks or projects demanding the work during many lesson units. "Task" is a key concept of linguistic description included in the Common European Framework of Reference for Languages and it offers a new dimension to the learning/teaching process. The implementation takes place in a specific environment, it implies a determined purpose (linguistic or/and extra-linguistic) and directs the learner's work. The task changes the teachers' roles, the didactics and their relations with students. In order to implement the task-based teaching to the educational practice we need some theoretical framework. The purpose of the article is to present examples of the "task" concept interpretation and its didactic implications in the context of action-oriented approach.

KEYWORDS: task; exercise; activity; action-oriented approach; CEFR; Task Based Learning and Teaching 


\section{POR QUE ESSE TEMA ?}

A análise da literatura sobre diferentes questões relativas ao Quadro Europeu Comum de Referência $(2001)^{2}$ demonstra que os níveis de competência e seus descritores são frequentemente abordados pelos utilizadores do documento. Menos frequentes, porém, são aqueles que examinam a questão das tarefas e a utilização dessas no processo de aprendizagem. É justamente o que propomos fazer neste artigo.

Abordamos então alguns problemas essenciais, ligados ao conceito de tarefa e a suas implicações pedagógicas como vistas pelo prisma do CECR e comentados por especialistas interessados na implementação de seus princípios. Uma parte essencial de nossas reflexões, portanto, diz respeito a diversos sentidos atribuídos à palavra "tarefa", e seu status no ensino/aprendizagem de línguas. Não é possível falar de tarefa sem traçar em algumas palavras as características principais da perspectiva acional, da qual a noção de tarefa é o núcleo duro.

\section{PERSPECTIVA/ABORDAGEM ACIONAL}

\section{O que é a perspectiva acional?}

A perspectiva acional adotada pelo Quadro é "antes de qualquer coisa uma reflexão sobre a ação" (BOURGUIGNON, 2010, p. 16). Ela se baseia no termo "ação", que os autores do documento utilizam com frequência, bem como em outras palavras pertencentes à mesma família: ator, agir, reagir, interagir, interação, transação ${ }^{3}$. Esse vocabulário aparece também nos descritores que tratam das competências: um utilizador da língua no âmbito da interação oral, no nível A1:

\footnotetext{
${ }^{2}$ A autora se baseia na versão em francês do Quadro Europeu Comum de Referência, daí a sigla $C E C R$, edição de 2001. Na tradução deste artigo, não levamos em consideração a versão portuguesa do documento ( $Q E C R)$, dadas as diferenças entre a variante lusitana e brasileira da língua portuguesa. (N.T.)

${ }^{3}$ No documento, deparamos com passagens como: “A perspectiva acional leva então também em conta os recursos cognitivos, afetivos, volitivos e o conjunto das capacidades que o autor social possui e põe em prática» (CECR, 2001, p. 15); "As competências são o conjunto de conhecimentos, de habilidades e de disposições que permitem agir." (idem) ; " $\mathrm{O}(\mathrm{s})$ interlocutor(es) poderia(m) ser submetidos a condições ou exigências parcial ou totalmente diferentes daquelas do utilizador/aprendiz e reagir diferentemente." (CECR, 2001, p. 44); “Assim, aprender a interagir supõe mais do que aprender a receber e a produzir enunciados. Damos em geral uma grande importância à interação no uso e aprendizagem da língua em razão do papel central que ela desempenha na comunicação. » $(C E C R, 2001$, p. 18).
} 


\title{
DOSSIÊ ESPECIAL: DIDÁTICA SEM FRONTEIRAS (orgs.) \\ CHEREM, RAMMÉ, PEDRA \& OLMO \\ Revista X, vol.2, 2014
}

É capaz de interagir de modo simples, mas a comunicação depende totalmente da repetição, em um ritmo de elocução mais lento, da reformulação e das correções. Ele pode responder e fazer perguntas simples, reagir e produzir afirmações simples relativas a suas necessidades imediatas ou a temas muito familiares (CECR, 2001, p. 61).

Quanto ao termo acional, os autores do Quadro europeu utilizam três termos relacionados a esse adjetivo: a perspectiva acional (\$ 2.1), a orientação acional (§ 2.1) et a abordagem acional ( $§ 4, \S 9$ 9.2.2.). Estas três formulações parecem ser sinônimas no documento, mas, como explicita J.M. Gautherot, ainda que a expressão "abordagem acional" concorra muitas vezes com "perspectiva acional”, é a última a mais pertinente no que se refere à coerência com o conjunto do projeto $C E C R(2009$, p. 171).

No capítulo 2 do Quadro, intitulado: Características de toda forma de uso e de aprendizagem de uma língua, os autores do documento definem a abordagem que adotam e a explicam:

\begin{abstract}
A perspectiva privilegiada aqui é, também bastante amplamente, de tipo acional, na medida em que considera o usuário e o aprendiz de uma língua como dois atores sociais que têm de efetuar tarefas (que não são somente linguísticas) em circunstâncias e em um meio dados, em uma área particular. Se os atos de fala se realizam em atividades linguísticas, estas por sua vez se inscrevem em ações num contexto social, ações estas que, por si só, dão-lhe plena significação. (CECR, 2001, p. 15).
\end{abstract}

A perspectiva acional leva em conta um novo objetivo no ensino/aprendizagem de línguas, um objetivo social ligado à integração europeia: trata-se de preparar os aprendizes (p. ex. por meio de uma abordagem fundamentada na realização de tarefas) para que possam integrar-se nos países da Europa pelos quais serão levados a circular; de preparar para viver e trabalhar em seus próprios países ou em um país estrangeiro, com nativos de diferentes línguas e culturas estrangeiras. "Não se trata mais de comunicar com o outro (de informar-se e de fornecer informações) mas, sim, de interagir com o outro em língua estrangeira" (PUREN 2004, p. 26) e agir sobre o outro.

Contudo, é preciso admitir que essa perspectiva não está descrita de maneira clara no $C E C R$ e que é necessário às vezes ler nas entrelinhas para percebê-la. Do ponto de vista metodológico, a perspectiva acional não faz senão reunir as práticas pedagógicas existentes, como: a abordagem comunicativa, a abordagem por tarefas ou a abordagem por competências ${ }^{4}$.

\footnotetext{
${ }^{4}$ Ver : BEACCO, J.-C. L'approche par compétences dans l'enseignement des langues, Paris : Didier, 2007.
} 


\title{
DOSSIÊ ESPECIAL: DIDÁTICA SEM FRONTEIRAS (orgs.)
}

CHEREM, RAMMÉ, PEDRA \& OLMO

Revista X, vol.2, 2014

\section{O Quadro se recusa a propor uma metodologia?}

Se por um lado fala-se de "abordagem adotada", por outro é possível perceber que o $C E C R$ se recusa a propor uma metodologia, o que faz é, antes, propor um amplo inventário de opções metodológicas de caráter não prescritivo: “O Quadro de referência não tem por vocação promover um método de ensino particular, mas sim apresentar escolhas" (CECR, 2001, p. 109) ${ }^{5}$.

Como ressalta J. -J. Richer (2009, p. 15), “no entanto a dimensão metodológica não está totalmente ausente no Quadro, pois ela é expressa através da noção de tarefa, que constitui o instrumento metodológico que permite concretizar a perspectiva acional". Basta analisar a passagem do CECR intitulada Características de toda forma de uso e aprendizagem de uma língua para constatar que existe uma associação estreita entre a competência para comunicar numa língua e a noção de tarefa.

\begin{abstract}
O uso de uma língua, incluindo sua aprendizagem, compreende ações realizadas por pessoas que, como indivíduos e como atores sociais, desenvolvem um conjunto de competências gerais e, especialmente, uma competência para se comunicar por meio da língua. Elas colocam em prática as competências de que dispõem em contextos e condições variadas, adaptando-se a diferentes limitações a fim de realizar atividades de linguagem que permitem tratar (na recepção e na produção) de textos que se referem a temas de áreas específicas, mobilizando as estratégias que parecem melhor convir para a conclusão das TAREFAS a realizar (CECR, 2001, p.15).
\end{abstract}

A tarefa concretiza a ativação da competência e mantém uma relação com a ação; as estratégias regulam as ações da linguagem.

\section{A TAREFA NA PERSPECTIVA ACIONAL}

\section{O que é uma tarefa?}

A tarefa como instrumento pedagógico já tem uma longa história. Suas origens remetem ao ensino profissional, em que a conclusão de uma tarefa, portanto a execução

\footnotetext{
${ }^{5}$ Ver também: $§ 2.3 .2$., p. $21 ;$; 6.4., § 6.4.1, p. 109 do CECR.
} 


\section{DOSSIÊ ESPECIAL: DIDÁTICA SEM FRONTEIRAS (orgs.) \\ CHEREM, RAMMÉ, PEDRA \& OLMO \\ Revista X, vol.2, 2014}

de uma atividade, era prova de que o aprendiz havia adquirido as habilidades necessárias para realizar um trabalho.

No que se refere ao ensino de línguas estrangeiras, a tarefa origina-se de pesquisas anglo-saxãs e o CECR se limita a fazer uma "redefinição" desta noção. Uma ampla utilização das tarefas pode ser observada na corrente metodológica chamada Task Based Learning and Teaching (T.B.L.T.) da qual os dois teóricos principais - D. Nunan e P. Skehan - aparecem nas referências bibliográficas do Quadro (CECR, 2001, p. 191). Trata-se de uma variante anglo-saxã da abordagem comunicativa que se baseia no princípio de que

\footnotetext{
“a aprendizagem de uma língua avançará com mais sucesso se o ensino visar simplesmente criar contextos nos quais a capacidade natural de aprendizagem dos alunos pode ser alimentada, ao invés de proceder de modo sistemático, ensinando elemento por elemento" (ELLIS, 2003, apud RICHER, 2012, p.125).
}

\section{Definições de tarefa no Quadro europeu comum de referência}

Os autores do Quadro definem o conceito nos seguintes termos: "Define-se como tarefa toda intenção acional que, para o ator, representa a necessidade de chegar a um dado resultado em função de um problema para resolver, de uma obrigação para cumprir, de uma meta estabelecida" (CECR, 2001, p. 16). Mas esta é apenas uma das definições que podemos ler no documento. Encontramos diversos trechos do CECR dedicados à tarefa, que reagrupamos abaixo. Na perspectiva acional do Quadro, a tarefa:

- é uma tarefa social que se inscreve num contexto social (p. 15, § 2.1.);

- é um conjunto de ações concluídas numa certa área com um objetivo definido e um resultado específico (p. 121, § 7.1.);

- mobiliza estratégias e competências plurais (p. 121, § 7.1.);

- pode ou não estar ligada à linguagem (ter uma componente linguística) (p. 19, § 2.1.5.);

- pode ser simples ou complexa (englobar tarefas intermediárias ou sub-tarefas) (p.121, $\S 7.1$.

- pode ser realizada de maneira individual ou coletiva (p. 15, § 2.1.). 


\section{DOSSIÊ ESPECIAL: DIDÁTICA SEM FRONTEIRAS (orgs.) \\ CHEREM, RAMMÉ, PEDRA \& OLMO \\ Revista X, vol.2, 2014}

Como se pode ver, ainda que o Quadro dedique um capítulo inteiro (capítulo 7) à explicitação das especificidades metodológicas de uma tarefa, a apresentação delas, adotada nesse documento, revela-se bastante abstrata (uma simples enumeração de características em diferentes partes do $C E C R$, falta de exemplos, de explicações, de referências) e não permite delimitar com precisão esse conceito. Aliás, os próprios autores reconhecem que "a definição dos limites de uma dada tarefa pode se tornar algo difícil de se fazer" (CECR, 2001, p. 121).

Assim sendo, só nos resta recorrer a definições de tarefa no T.B.L.T. (a fonte para os autores do Quadro), para uma melhor compreensão desse conceito.

\section{A tarefa no Task Based Learning and Teaching}

Os criadores da T.B.L.T definiram a tarefa de diferentes maneiras. As definições mais conhecidas são as de J. Willis, D. Nunan P. Skehan e R. Ellis.

Segundo J. Willis (1996, p. 23), a tarefa é uma atividade durante a qual o aprendiz utiliza a língua-alvo com um fim (objetivo) comunicativo para atingir um resultado ${ }^{6}$.

Para D. Nunan, (2004, p. 4) uma tarefa é um exemplo de trabalho escolar que implica/envolve os aprendizes na compreensão, na manipulação, na produção ou na interação na língua alvo enquanto sua atenção está mais focada no sentido que na forma ${ }^{7}$.

P. Skehan (1996, p. 38) considera que numa tarefa é o sentido que é fundamental, há um problema de comunicação para resolver, há uma relação com atividades comparáveis do mundo real, a realização da tarefa é prioritária e a avaliação da tarefa se faz a partir do resultado ${ }^{8}$.

\footnotetext{
${ }^{6}$ [Task is an activity] where the target language is used by the learner for a communicative purpose (goal) in order to achieve an outcome (WILLIS, 1996, p. 23).

${ }^{7}$ [Task is] a piece of classroom work which involves learners in comprehending, manipulating, producing or interacting in the target language while their attention is principally focused on meaning rather than form. (NUNAN, 2004, p. 4)

${ }^{8}$ A task is an activity in which: meaning is primary; there is some communication problem to solve; there is some sort of relationship to comparable real-word-activities; task completion has some priority; the assessment of task is in terms of outcome (SKEHAN, 1996, p. 38).
} 


\title{
DOSSIÊ ESPECIAL: DIDÁTICA SEM FRONTEIRAS (orgs.) \\ CHEREM, RAMMÉ, PEDRA \& OLMO \\ Revista X, vol.2, 2014
}

R. Ellis (2003, p. 4-5), além das definições mencionadas acima, cita em sua obra seis outras definições, bem como apresenta alguns traços do conceito de tarefa ${ }^{9}$. Para ele, a tarefa:

- é um plano de trabalho;

- é focada no sentido;

- consiste em resolver um problema de comunicação;

- implica a utilização da língua em situações reais;

- implica a implementação de quatro atividades de língua;

- ativa processos cognitivos;

- dá lugar a um resultado identificável (ELLIS, 2003, p. 9-10).

Diante disso, temos que admitir que o que encontramos no capítulo 7 do Quadro europeu são justamente as características da tarefa elaboradas pelo T.B.L.T., a definição que segue sendo apenas um tímido recurso a definição do T.B.L.T..

\begin{abstract}
As atividades de sala de aula, quer "autênticas" ou essencialmente "pedagógicas" são comunicativas na medida em que elas exigem dos alunos que eles compreendam, negociem e exprimam o sentido delas a fim de atingir um objetivo comunicativo. Numa tarefa comunicativa, a foco é colocado no sucesso da execução da tarefa e, consequentemente, o sentido está no centro do processo enquanto os aprendizes realizam suas intenções comunicativas (CECR, 2001, p. 121).
\end{abstract}

\section{Tipologia das tarefas}

Outro problema que se apresenta quando nos referimos a tarefas é sua classificação. A que se baseia na interpretação dos textos de $C E C R$ varia de um autor para outro. Em geral, os especialistas distinguem entre duas e cinco categorias de tarefas.

De acordo com E. Rosen, o Quadro classifica as tarefas em duas grandes categorias: as tarefas "próximas da vida real", escolhidas em função das necessidades do aluno fora de sala de aula ou do contexto de aprendizagem; as tarefas "pedagógicas comunicativas" nas quais os alunos se engajam numa "simulação aceita voluntariamente" para interagir utilizando a língua-alvo. O que alguns autores chamam

\footnotetext{
${ }^{9}$ De acordo com M. Breen (1989), M. Long (1985), J. Richard, J. Platt i H. Weber (1985), G. Crookes (1986), N. S. Prabhu (1987), D. Nunan (1989), P. Skehan (1996), J. F. Lee (2000), M. Bygate, P. Skehan e M. Swain (2001).
} 


\section{DOSSIÊ ESPECIAL: DIDÁTICA SEM FRONTEIRAS (orgs.) \\ CHEREM, RAMMÉ, PEDRA \& OLMO \\ Revista X, vol.2, 2014}

de uma "terceira categoria de tarefas" são apenas "exercícios voltados para a manipulação de formas na ausência de qualquer contexto" (ROSEN, 2007, p. 20).

Já no Dicionário prático do CECR J.-P. Robert e E. Rosen falam de cinco tipos de tarefas. Essa classificação é enriquecida pelo conteúdo do Guia para os utilizadores do Quadro (2001):

O Quadro, mesmo isso não tendo sido colocado de modo explícito em nenhum momento, distingue cinco tipos de tarefas:

- $\quad$ as tarefas autênticas da vida real;

- $\quad$ as tarefas "alvo", "de repetição" ou "próximas da vida real";

- $\quad$ as tarefas pedagógicas comunicativas;

- $\quad$ as tarefas de pré-comunicação;

- $\quad$ as tarefas "meta-comunicativas.” (ROBERT; ROSEN, 2010, p. 272).

De onde vêm essas diferenças na tipologia? A causa principal desse malentendido é, entre outras, a falta de uma distinção precisa entre a noção de tarefa e a de exercício: para uns, toda atividade em sala de aula de língua é chamada de "tarefa", para outros, tarefa e exercícios não são sinônimos. Nós distinguimos: tarefas autênticas, tarefas pedagógicas comunicativas e tarefas ou antes exercícios de pré-comunicação ( $c f$. 2.6.) conforme ilustra o esquema a seguir:

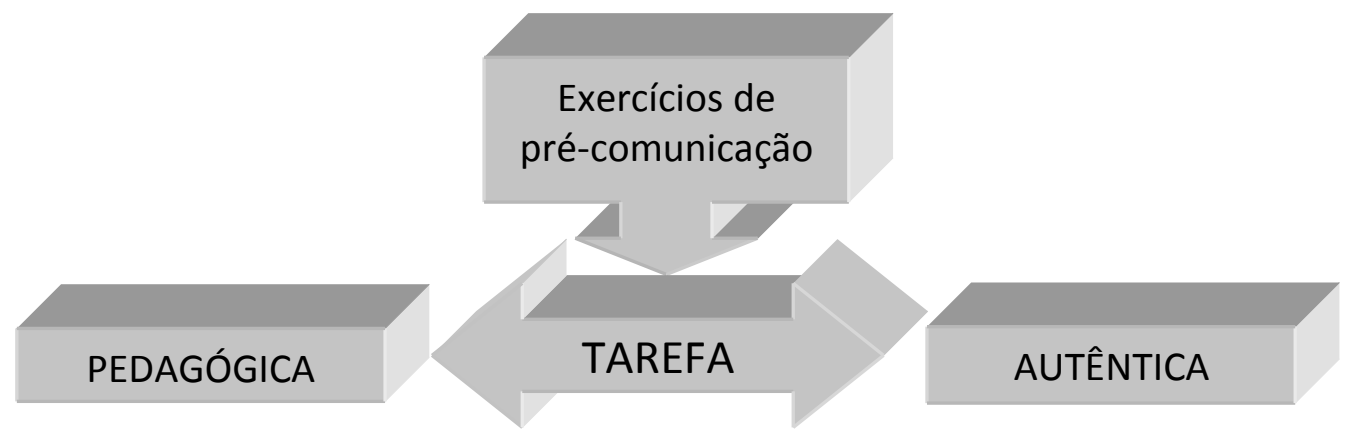

Figura 1: Tipologia das tarefas

O papel das tarefas/exercícios de pré-comunicação consiste em fornecer um meio que permitiria ao aluno construir competências de linguagem adaptadas a situações de comunicação. Deste modo, situamos a tarefa num eixo entre um polo autêntico e um polo pedagógico conforme ela se aproxima de uma prática linguística e/ou não linguística referente ao mundo real ou permite aos aprendizes desenvolver as competências necessárias para funcionar em situações comunicativas do mundo exterior. 


\title{
Complexidade da tarefa
}

Pode-se também classificar as tarefas de acordo com sua complexidade. Como se vê no Quadro:

\begin{abstract}
Uma tarefa pode ser bastante simples ou, ao contrário, extremamente complexa (por exemplo, o estudo de um certo números de planos e de instruções para montar um aparelho complicado e desconhecido). O número de etapas ou de tarefas intermediárias pode ser mais ou menos grande e, consequentemente, a definição dos limites de uma tarefa dada pode tornar-se difícil." (CECR, 2001, p. 121)
\end{abstract}

Uma tarefa complexa ou macrotarefa engloba tarefas intermediárias, microtarefas ou subtarefas que chamamos às vezes de etapas (cf. CECR 2001, DEMAIZIÈRE; NARCY-COMBES 2005. NISSEN, 2013). Podemos também falar de uma sequência de tarefas em script, de uma sequência de tarefas ou de um encadeamento de diversas tarefas, e, enfim, de um projeto implicando várias tarefas. "A subtarefa (ou etapa) está diretamente orientada para a realização de uma tarefa final e é parte integrante dela" (NISSEN, 2013, p. 14). Por exemplo: coletar informações antes de estabelecer um planejamento para uma excursão escolar.

"Uma tarefa simples demanda uma só capacidade mesmo se ela exige a utilização de vários conhecimentos; uma tarefa complexa demanda várias capacidades" (BOURGUIGNON, 2010, p. 27). É o que ilustra o quadro abaixo:

\begin{tabular}{|l|l|}
\hline \multicolumn{1}{|c|}{ TAREFA } & \multicolumn{1}{|c|}{ EXEMPLO } \\
\hline & $\begin{array}{l}|c| \\
\text { Tarefa complexa: }\end{array}$ \\
Alugar um apartamento em Cracóvia & ler anúncios para poder escolher um \\
& - escrever um email ou telefonar para o \\
& proprietário \\
& - encontrar o proprietário e assinar o \\
& contrato \\
\hline Tarefa simples: & - ler e compreender anúncios \\
\hline Ler um texto & \\
\hline
\end{tabular}

Quadro 1. Tarefas simples e complexas: exemplos 


\section{Tarefa e exercício}

Mas para realizar uma tarefa é preciso igualmente recorrer aos exercícios. Os pontos de vista sobre tarefas e exercícios não são unânimes. D. Coste, um dos coautores do $C E C R$, não faz diferença entre "tarefa" e "exercício".

Todo "exercício" que entra numa sequência de ensino é considerado como tarefa (na medida em que há enunciado, objetivo, resultado observável e avaliável). Assim considerados, um ditado, um questionário de múltipla escolha, um texto com lacunas para completar são tarefas tanto quanto uma simulação global ou a preparação de uma exposição (cartazes, placas, envio de convites, cobertura fotográfica ou vídeo etc.) ou um diário das atividades de sala de aula (COSTE, 2009, p. 17).

Mas há também especialistas que se opõem a esse ponto de vista, como C. Springer (2009) ou M. Denyer (2009). O Quadro, por sua vez, também não propõe nenhuma definição de exercício, embora estabeleça distinção entre os "exercícios formais", fora de contexto, e as tarefas pedagógicas comunicativas. No $§$ 6.4.7.8 desse documento, os autores apresentam uma tipologia dos exercícios ditos formais.

Se utilizamos exercícios formais, eles podem ser dos seguintes tipos:

a. textos com lacunas

b. construção de frases a partir de um modelo dado

c. exercícios de múltipla escolha

d. exercícios de substituição relativos a uma categoria (por exemplo, singular/plural, presente/passado, voz ativa/passiva etc.)

e. combinação de frases (por exemplo, relativas, proposições adverbiais e nominais etc.)

f. tradução de frases da L1 para a L2

g. perguntas/respostas que levam à utilização de certas estruturas

h. exercícios de desenvolvimento da fluência linguística centrados na gramática etc. (CECR, 2001, p. 116).

O documento, porém, previne seus utilizadores de que, mesmo que esses exercícios facilitem a aquisição de competências comunicativas, eles não são suficientes para que os alunos possam se comunicar.

Mas fazemos questão de ressaltar aqui que a tarefa não é um exercício. C. Springer lembra que foi por intermédio da metodologia audiovisual que o exercício passou a ser considerado como unidade mínima de aprendizagem. 


\section{DOSSIÊ ESPECIAL: DIDÁTICA SEM FRONTEIRAS (orgs.) \\ CHEREM, RAMMÉ, PEDRA \& OLMO \\ Revista X, vol.2, 2014}

O exercício está então, por tradição, intimamente ligado ao trabalho com a língua, e para nós assim ele deve permanecer, se desejamos que a nova noção de tarefa ganhe espaço. É um trabalho puramente escolar, formal, sistemático, repetitivo, limitado. Dizendo de outro modo: trata-se de criar automatismos, de colocar em prática procedimentos automatizados, operações pré-formatadas (SPRINGER, 2009, p. 29).

Este autor observa assim que a tarefa não é um exercício e, no $C E C R$, ela "é considerada como uma maneira de enxergar a ação do aluno-ator social (idem). Para esclarecer, propomos a distinção entre três tipos de atividades de sala de aula na perspectiva acional e na abordagem por tarefas (JANOWSKA, 2011, p. 179):

- Tarefa social (autêntica) cujo objetivo é a ação social, isto é, a resolução de problema(s). É a tarefa complexa, na maioria dos casos autêntica ${ }^{10}$, que exige operações cognitivas sociais e que mobiliza recursos transversais e de linguagem diversos. Está situada num contexto, leva a um resultado identificável e pressupõe a autonomia do aprendiz.

Exemplo $^{11}$ : É uma tarefa que se compõe de três etapas e exige dos estudantes/ alunos uma cooperação intensa. ${ }^{12}$

\footnotetext{
${ }^{10}$ D. Nunan $(2004$, p. 20$)$ considera que qualquer tarefa autêntica torna-se « pedagógica » em sala de aula.

${ }^{11}$ Os exemplos apresentados neste artigo originam-se na prática de ensino de polonês língua estrangeira, nível B1.

${ }^{12}$ A tarefa em questão, como observado anteriormente pela autora, refere-se à locação de um apartamento. No texto reproduzido, são dadas a tarefa principal e as subtarefas. N.T.
} 


\section{DOSSIÊ ESPECIAL: DIDÁTICA SEM FRONTEIRAS (orgs.)}

CHEREM, RAMMÉ, PEDRA \& OLMO

Revista X, vol.2, 2014

ZADANIE: wybrać mieszkanie i umeblować je...

Po ukończeniu studiów w Polsce, trzem osobom z grupy zaproponowano pracę w prestiżowym przedsiębiorstwie.

Zakład pracy dysponuje dwoma służbowymi mieszkaniami, ale nie są one umeblowane. Pracując w trzyosobowych grupach proszę dokonać wyboru jednego z mieszkań i umeblować je.

1. Po obejrzeniu planów, wybierzcie mieszkanie, które najbardziej Wam odpowiada. Proszę uzasadnić ten wybór.

2. Rozplanujcie, kto będzie mieszkał w poszczególnych pokojach i dlaczego.
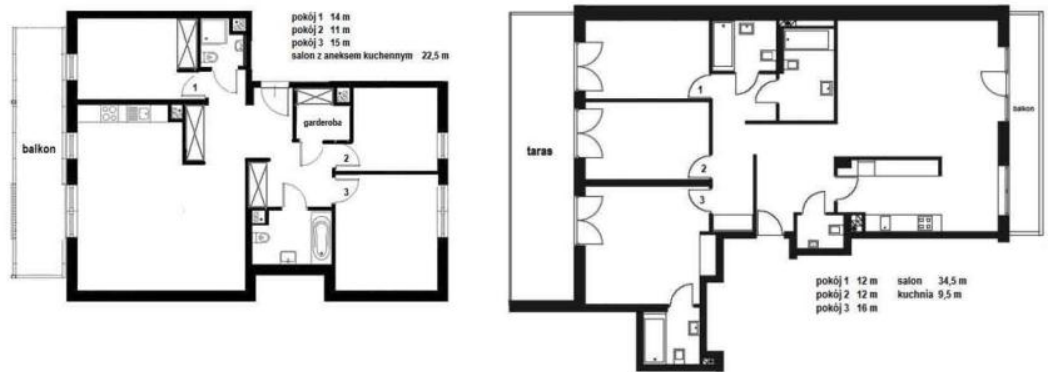

3. Mieszkanie, które wybraliście nie jest umeblowane. Zastanówcie się wspólnie, jakich mebli potrzebuje każdy z was i zaproponujcie ich rozmieszczenie w poszczególnych pomieszczeniach.

Na wybrany plan proszę nanieście meble, które są niezbędne do zamieszkania, a następnie przedstawcie tę propozycje wszystkim kolegom i wysłuchajcie ich opinii.

- Tarefa comunicativa (pedagógica) cujo objetivo é a comunicação através da linguagem.

É uma tarefa simples que ajuda o aprendiz a relacionar as atividades linguísticas de compreensão, produção, interação e mediação.

Exemplo: Trata-se aqui de uma única atividade - atividade de compreensão escrita $^{13}$.

\footnotetext{
${ }^{13}$ Nesta tarefa, os aprendizes devem relacionar os anúncios imobiliários com as imagens. N.T.
} 


\section{DOSSIÊ ESPECIAL: DIDÁTICA SEM FRONTEIRAS (orgs.) \\ CHEREM, RAMMÉ, PEDRA \& OLMO}

Revista X, vol.2, 2014

Przeczytaj ogłoszenia i dopasuj je do zdjęć budynków.

1. Stylowy dworek do wynajęcia
o powierzchni ok. $350 \mathrm{~m}^{2}$;
6 pokoi, 3 łazienki, sala balowa,
położony w okolicach Warszawy;
w pełni wyposażony.

1. Stylowy dworek do wynajęcia w pełni wyposażony

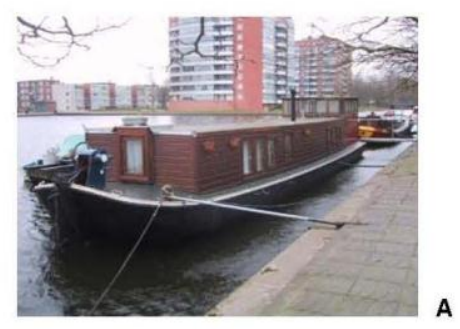

2. Do sprzedania lub wynajęcia mieszkanie w odrestaurowanej kamienicy $\left(75 \mathrm{~m}^{2}\right)$ w centrum miasta, w sq̨siedzłwie Ogród Botaniczny; studioB@krakow.pl
3. Do sprzedania stylowy dom góralski z działką o usytuowany w poblizi Zakopanego, z dala od miejskiego hałasu. Kontakt: biuro nieruchomości „Loco”, Zakopane, ul. Krupówki $12 \mathrm{c}$

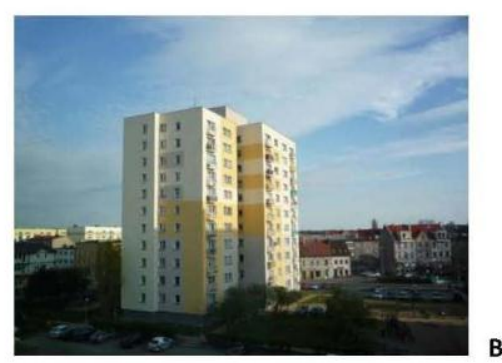

B

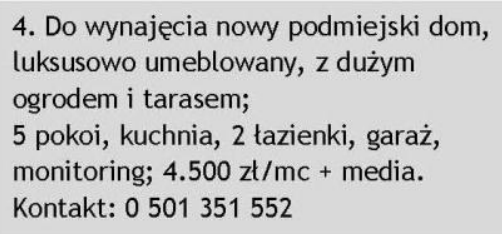

4. Do wynajęcia nowy podmiejski dom, luksusowo umeblowany, z dużym ogrodem i tarasem;

5 pokoi, kuchnia, 2 tazienki, garaż, monitoring; $4.500 \mathrm{zt} / \mathrm{mc}+$ media. Kontakt: 0501351552

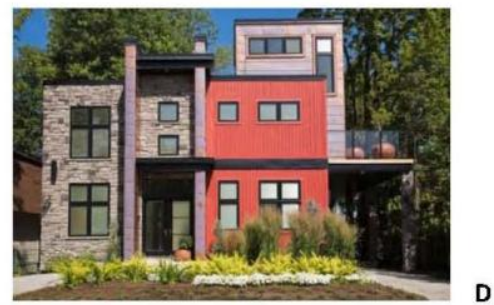

6.Do wynajęcia: $56 \mathrm{~m}^{2} \mathrm{w}$ wieżowcu, Piękne widoki na całe miasto o każdej mieszkanie, na 10 piętrze. porze roku.

5. Dom na wodzie, gwarantuje całkowitą wolność, nie wymaga ani mebli, ani sprzątania. $46 \mathrm{~m}^{2}$ powierzchni użytkowej. Cena przystępna. Lokalizacja według uznania właściciela.

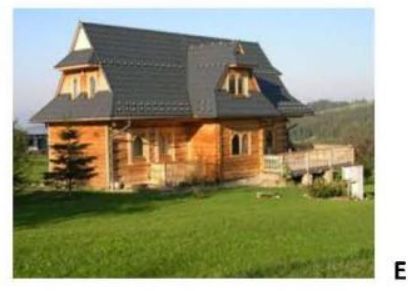

E

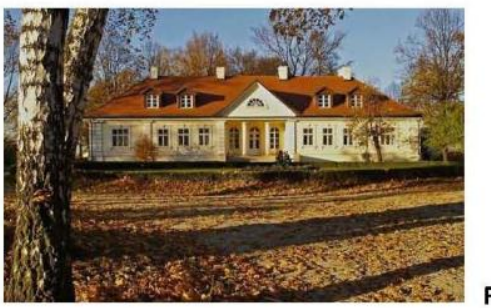

- Exercício (de pré-comunicação) cujo objetivo é a aquisição dos saberes linguísticos dos quais o aprendiz necessitará para realizar as tarefas comunicativas e sociais. Os exercícios são organizados em torno da manipulação de formas fora de contexto. Aqui servimo-nos de operações elementares como identificar, reconhecer, reutilizar. 


\section{DOSSIÊ ESPECIAL: DIDÁTICA SEM FRONTEIRAS (orgs.) \\ CHEREM, RAMMÉ, PEDRA \& OLMO \\ Revista X, vol.2, 2014}

Exemplo: Propõe-se aos aprendiz fazer dois exercícios lexicais que consistem em escolher e preencher lacunas com as formas adequadas.

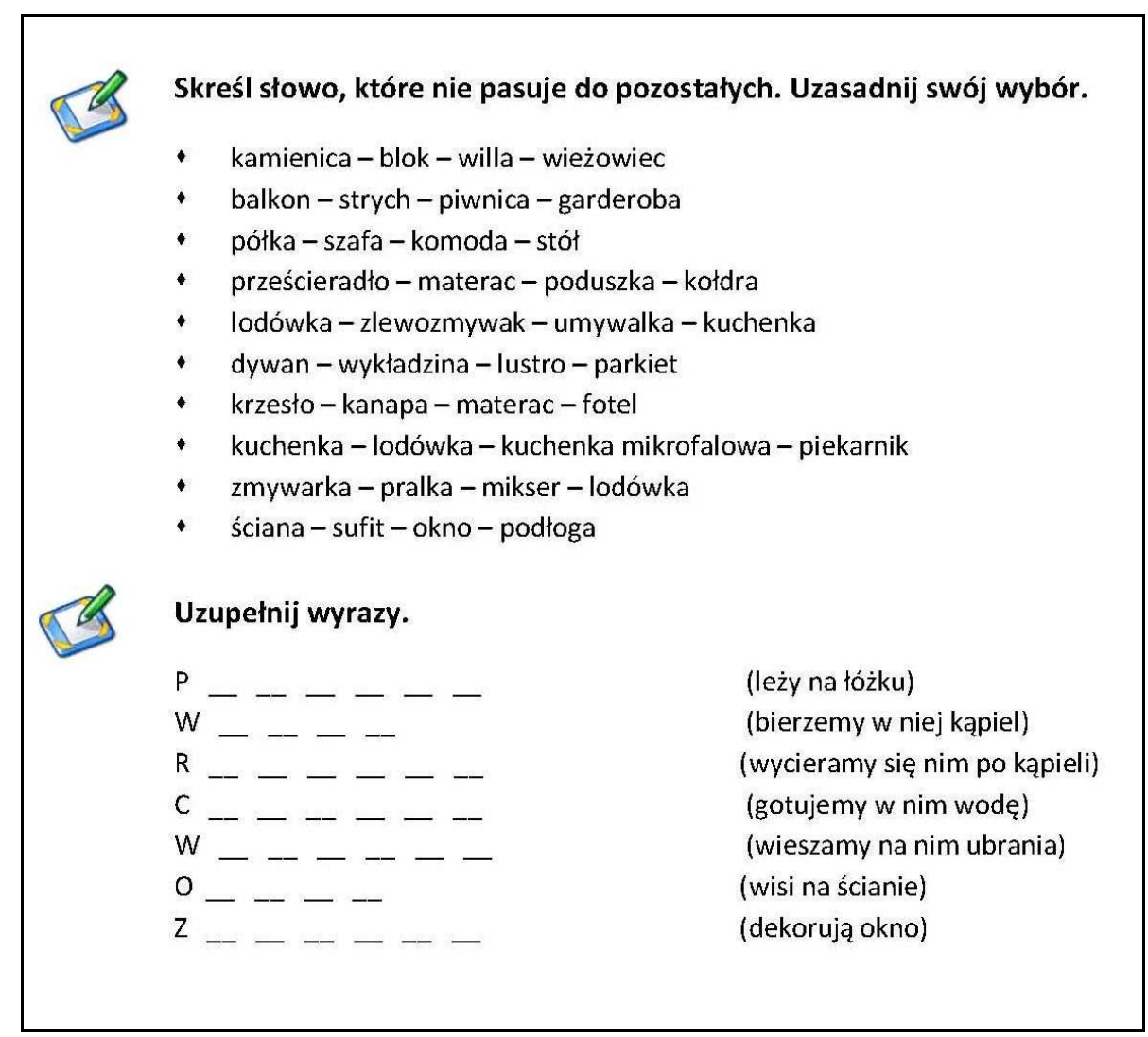

É preciso observar que o exercício é a base de todo trabalho de sala de aula. A abordagem por tarefas não somente não exclui diferentes tipos de exercícios (de gramática, léxico, ortografia) mas necessita deles para que o aprendiz torne-se mais eficaz. "O exercício pode assim ser considerado como uma atividade que visa a aquisição, a instalação, a automatização de um recurso, condição indispensável para a posterior mobilização destas.” (DENYER, 2009, p. 151).

A distinção entre "exercícios" e "tarefas" (comunicativas e sociais) é necessária para tornar a passagem da aprendizagem para o uso de língua mais claro aos olhos dos professores, que devem estar conscientes de que neste processo nunca se deve "queimar etapas”. Como observa C. Bourguignon (2010, p. 28) "Não pode haver 'competência' sem um grau de domínio de 'saber' e de 'saber-fazer'”. É o que representamos por meio do esquema que segue: 


\section{DOSSIÊ ESPECIAL: DIDÁTICA SEM FRONTEIRAS (orgs.)}

CHEREM, RAMMÉ, PEDRA \& OLMO

Revista X, vol.2, 2014

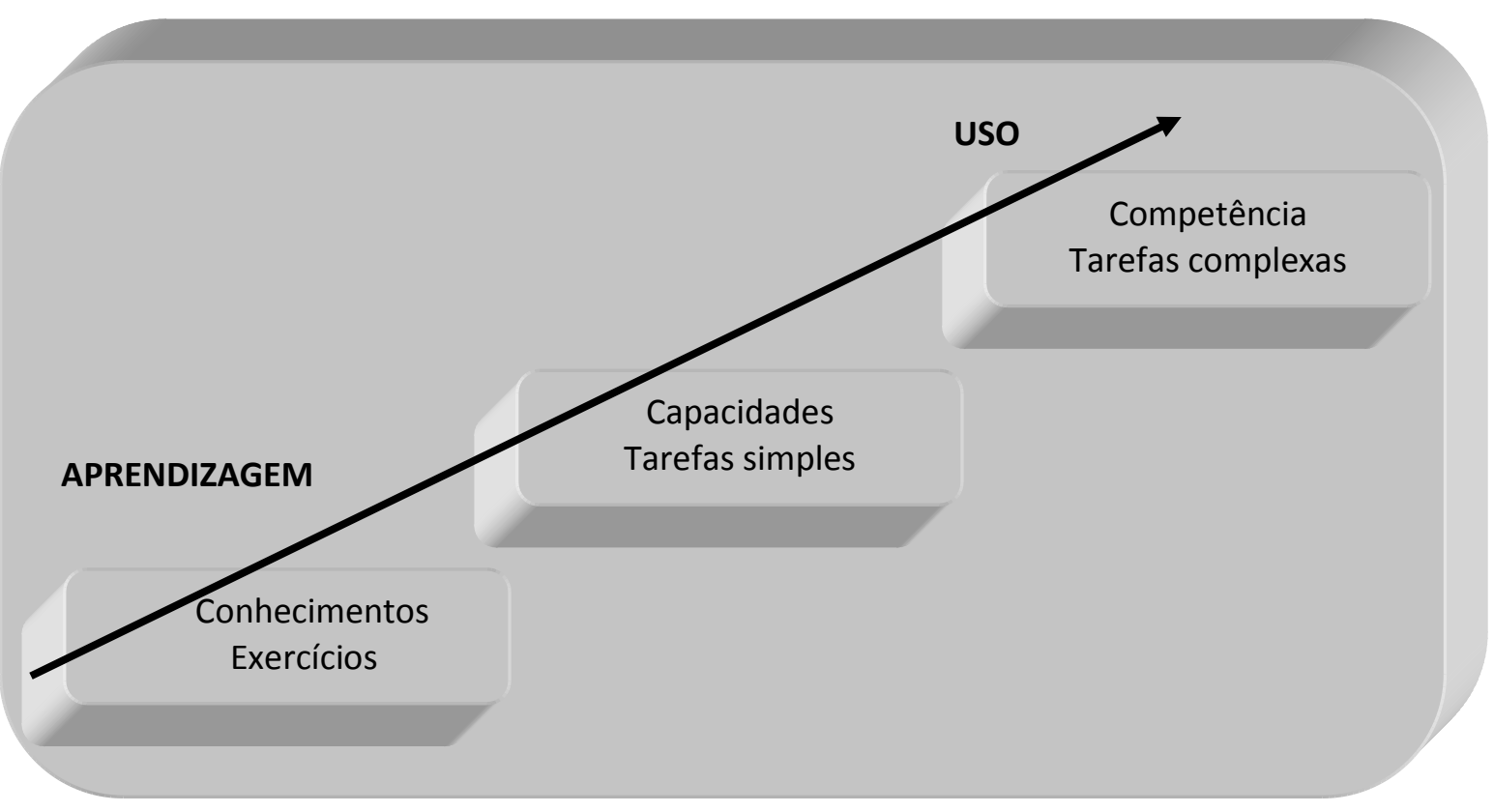

Imagem 2. As diferentes etapas para atingir a competência (BOURGUIGNON, 2010, p. 28)

\section{Tarefas, competências e ação}

Na abordagem proposta no Quadro comum, a competência para comunicação através da linguagem é indissociável da ação: linguística, física ou intelectual. Para os autores do Quadro, "as competências são o conjunto dos conhecimentos, das habilidades e das disposições que permitem agir" (CECR, 2001, p.15). É por isso que, na realização de uma tarefa em situação pedagógica é preciso levar em conta, em primeiro lugar, as competências do aprendiz/utilizador da língua: suas competências gerais e sua competência para se comunicar que se concretizam nas atividades de linguagem. Não é possível transmitir ou adquirir diretamente uma competência. Ela se desenvolve através da ação. A competência é "conhecimento em ação" (PERRNOUD, 1997).

Como a ênfase é dada às competências, é preciso que possamos criar um meio de ação favorável ao seu desenvolvimento. Do ponto de vista metodológico, a noção de tarefa, tal qual emerge da perspectiva acional, parece responder plenamente à necessidade de coerência entre a teoria subjacente ao CECR e as práticas concretas da sala de aula. Numa tarefa há sempre uma ação motivada por um objetivo e um resultado identificável. 


\section{DOSSIÊ ESPECIAL: DIDÁTICA SEM FRONTEIRAS (orgs.) \\ CHEREM, RAMMÉ, PEDRA \& OLMO \\ Revista X, vol.2, 2014}

\section{ALGUMAS CONSIDERAÇÕES SOBRE A REALIZAÇÃO DAS TAREFAS}

Como dissemos anteriormente, e observam vários autores ( $c f$. RICHER, 2012), o CECR carece de sugestões pedagógicas, ele se recusa a propor uma metodologia. O "como" não é considerado e, de acordo com os autores do documento, "os métodos a serem postos em prática para a aprendizagem, o ensino e a pesquisa são aqueles considerados mais eficazes para atingir os objetivos convenientes em função dos aprendizes implicados em seu ambiente social" (CECR, 2001, p. 110). O documento não propõe portanto soluções prontas, princípios ou regras referentes ao emprego das tarefas no ensino/aprendizagem de línguas.

Sendo assim, nesta seção, para mostrar como podemos nos servir das tarefas em sala de aula, vamos recorrer, novamente, a pesquisas anglo-saxãs, e também a nossa própria experiência, ou seja, a nossas pesquisas sobre a utilização de tarefas no ensino de polonês língua estrangeira ( $c f$. JANOWSKA, 2011).

Analisemos então o encaminhamento proposto por J. Willis (1996, 2007), que divide a realização de tarefas em três partes. A primeira fase - Pre-task - é o momento em que o professor apresenta o tema, explorando-o e sensibilizando os aprendiz para o vocabulário e as estruturas que serão úteis quando da execução da tarefa. É o momento de mobilizar os conhecimentos já adquiridos pelos alunos e de motivá-los. A fase número 2 - Task cycle - é o momento da realização da tarefa. Em pequenos grupos ou em duplas, os estudantes preparam um relatório escrito ou oral para a turma (realização da tarefa, decisões, descobertas, etc). No final dessa fase, os grupos apresentam seus relatórios ou trocam seus textos a fim de comparar os resultados do trabalho. Ao longo da última sequência - Language focus - os aprendizes analisam as características dos textos e discutem sobre eles para passar em seguida à prática, isto é, aos exercícios em torno das novas palavras e estruturas encontradas.

O dia a dia da sala de aula com frequência se afasta bastante de esquemas préestabelecidos. O que apresentamos acima parece ser muito geral e os professores precisam de um script mais detalhado; o que são obrigados a preparar servindo-se de exemplos concretos, utilizando amostragens de língua e/ou exercícios.

Com base em nossas próprias observações, é muito importante explorar, sobretudo na primeira fase, o saber e o saber-fazer dos aprendizes. Os grupos nunca são homogêneos no que diz respeito ao nível linguístico de seus membros e ao 


\section{DOSSIÊ ESPECIAL: DIDÁTICA SEM FRONTEIRAS (orgs.) \\ CHEREM, RAMMÉ, PEDRA \& OLMO \\ Revista X, vol.2, 2014}

conhecimento de mundo destes. "Ensinar aos outros aquilo que alguns já sabem” é um princípio a se considerar em cada etapa da realização das tarefas.

Nada é dito tampouco sobre a extensão das aulas, nem sobre a duração das sucessivas etapas. O fator tempo tem um papel importante no planejamento e na realização das tarefas. Não seria exagero dizer que o sucesso ou o fracasso da aprendizagem dependem dele.

O esquema de J. Willis não precisa qual o papel do professor durante a realização da tarefa. Diz-se apenas que "o professor está presente, mas intervém pouco". De acordo com os resultados das pesquisas que fizemos, uma autonomia "absoluta" existe somente em teoria; a prática da abordagem acional demonstra que os aprendizes precisam de ajuda, que o professor deve se integrar ao grupo para dar sugestões, para orientar, guiando de modo discreto o conjunto dos encaminhamentos.

A opinião de Ch. Puren, citada logo abaixo, parece confirmar nossas observações. Este autor propõe a definição didática mais abstrata possível do conceito de "tarefa", mas essa definição permite observar que a tarefa e sua realização não implicam somente os alunos. A tarefa para ele é uma "unidade de atividade no interior do processo conjunto de ensino/aprendizagem" (PUREN, 2004, p. 15).

Resumindo, esquemas, indicações, propostas etc. constituem um tipo de bússola que orienta os participantes do processo didático de maneira geral e indica as grandes linhas da aprendizagem por tarefas. Mas isso não resolve o problema porque todo encaminhamento deve ser flexível e de acordo com o público e com as condições de ensino/aprendizagem.

Em todos os casos, a concepção de uma tarefa exige o cruzamento de uma análise fina do suporte com objetivos (em termos de apropriação) a fim de suscitar atividades de linguagem que sejam ricas, atentando-se para o dispositivo espaço-temporal e humano: presencial ou autoaprendizagem, interações entre pares, modo de avaliação, utilização ou não de multimídia (CUQ, 2003, p. 234). 


\section{DOSSIÊ ESPECIAL: DIDÁTICA SEM FRONTEIRAS (orgs.) \\ CHEREM, RAMMÉ, PEDRA \& OLMO \\ Revista X, vol.2, 2014}

\section{REFERÊNCIAS BIBLIOGRAFICAS}

BEACCO, J.-C. L'approche par compétences dans l'enseignement des langues. Paris : Didier, 2007.

BOURGuignON, C. Pour enseigner les langues avec le CECRL. Clés et conseils. Paris : Delagrave Edition, 2010.

CONSEIL DE L'EUROPE. Cadre européen commun de référence pour les langues. Apprendre, enseigner, évaluer. Strasbourg-Paris : Didier, 2001.

COSTE, D. Tâche, progression, curriculum. Le français dans le monde - Recherches et applications 45, 2009, pp. 15-24.

CUQ J.-P. (ed.). Dictionnaire de didactique du français langue étrangère et seconde. Paris : CLE International, 2003.

DEMAIZIERE, F., NARCY-COMBES J.-P.. Méthodologie de la recherche didactique : nativisation, tâches et TIC. Alsic. Vol. 8. $\mathrm{n}^{\circ}$ 1. 2005.Disponível em : http://alsic.revues.org/326.

DENYER, M. 2010. La perspective actionnelle du 'Cadre européen commun de référence' et ses répercussions dans l'enseignement des langues. In : LION-OLIVIERI, M.-L. ; LIRIA, Ph. (ed.). L'approche actionnelle dans l'enseignement des langues. Onze articles pour mieux comprendre et faire le point. Barcelone-Paris : Difusión, Editions Maison des langues, 2010, pp. 141-155.

ELLIS, R. Task-Based Language Learning and Teaching. Oxford: OUP, 2003.

GAUTHEROT, J.-M. Glossaire des termes du CECR. Le français dans le monde Recherches et applications. $\mathrm{N}^{\circ}$. 45, p.169-191, 2009.

JANOWSKA, I. Podejście zadaniowe do nauczania i uczenia się języków obcych. Na przykładzie języka polskiego jako obcego. Kraków: Universitas, 2011.

NISSEN, E. Variations autour de la tâche dans l'enseignement/apprentissage des langues aujourd'hui. Alsic. Vol. 14, 2011. Disponível em : http://alsic.revues.org/2344.

NUNAN D. Task-Based Language Teaching. Cambridge: CUP, 2004.

PERRENOUD, Ph. Construire des compétences dès l'école. Paris : E.S.F, 1997.

PUREN, Ch. De l'approche par les tâches à la perspective co-actionnelle. Les Cahiers de l'APLIUT. Vol. XXIII n ${ }^{\circ}$ 1, p. 10-26, 2004.

RICHER, J.-J. Lectures du 'Cadre' : continuité ou rupture ? In : LION-OLIVIERI, M.L. ; LIRIA, Ph. (ed.). L'approche actionnelle dans l'enseignement des langues. Onze articles pour mieux comprendre et faire le point. Barcelone-Paris : Difusión, Editions Maison des langues, p. 13-48. 2009.

RICHER, J.-J. La didactique des langues interrogée par les compétences. Bruxelles : E.M.E. \& InterCommuniactions, 2012.

ROBERT, J.-P.; ROSEN, E. Dictionnaire pratique du CECR. Paris : Editions Ophrys, 2010.

ROSEN, E. Le point sur le Cadre européen commun de référence pour les langues. Paris : CLE International, 2007.

SKEHAN, P. A Framework for the Implementation of Task-based Instruction. Applied Linguistics 17, p. 38-42. 1996.

SPRINGER, C. La dimension sociale dans le CECR: pistes pour scénariser, évaluer et valoriser l'apprentissage collaboratif. Le français dans le monde - Recherches et application 45. 25-34. 2009.

WILLIS J. A Framework for Task-Based Learning. London: Longman, 1996. WILLS, D.; WILLIS, J. Doing Task-based Teaching. Oxford: OUP, 2007. 